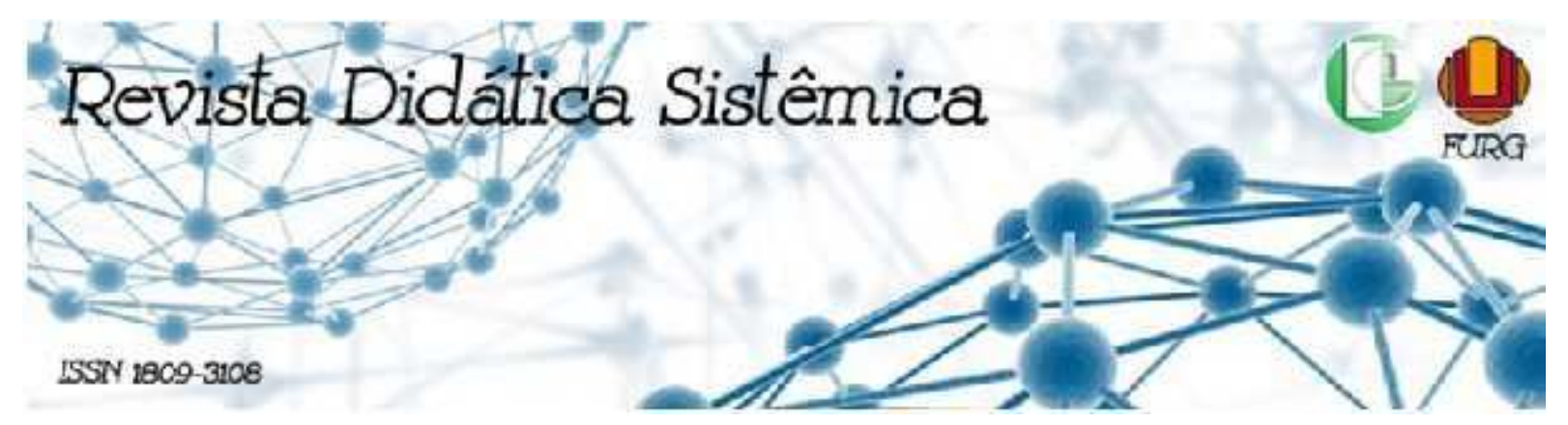

\title{
CONSTITUIÇÃO DA EDUCAÇÃO FÍSICA NA EDUCAÇÃO INFANTIL DO MUNICÍPIO DO RIO GRANDE (RS): PERSPECTIVAS PARA UMA SOCIOLOGIA DA INFÂNCIA
}

\section{RESUMO}

Camila Borges Ribeiro ${ }^{1}$ Josiane Vian Domingues ${ }^{2}$

Este artigo tem como objetivo discorrer sobre a constituição do lugar da Educação Física na Educação Infantil, no município do Rio Grande, estado do Rio Grande do Sul. Para tanto, fez-se uso de trabalhos acadêmicos, editais dos concursos públicos municipais e documentos legais. Constatamos que a inserção do/a professor/a de Educação Física, nessa etapa de ensino no município, é recente, pois a primeira nomeação, em cargo efetivo, se deu em 2015, contabilizando, atualmente, 16 docentes efetivos/as. Tal fato não atende a todas as escolas municipais, mas integra um movimento estimulado pelos projetos de lei que trataram dessa questão. Esse cenário também reflete a escassa literatura produzida sobre a Educação Física na Educação Infantil local. Dessa forma, concluímos que, ao direcionarmos nosso olhar para a história (re)conhecendo-a, podemos identificar suas potencialidades e fragilidades para pensar estratégias a fim de qualificar a ação docente. Assim como registrá-la, nos permite formar arcabouço teórico que incitem futuras reflexões e ações nesse campo.

Palavras-chave: Educação Física. Educação infantil. Infância.

\section{CONSTITUTION OF PHYSICAL EDUCATION IN CHILDHOOD EDUCATION IN RIO GRANDE CITY (RS): PERSPECTIVER FOR A SOCIOLOGY OF CHILDHOOD}

\begin{abstract}
This article aims to describe the constitution of the place of Physical Education in Childhood Education in Rio Grande city, Rio Grande do Sul state. For that purpose we researched academic works, civil service announcements of Rio Grande city and legal documents. We found that the insertion of the Physical Education teacher in this stage of teaching in the city is recent, since the first appointment in effective position took place in 2015 , currently counting 16 effective P. E. teachers. This fact does not serve all municipal schools, but it is part of a movement stimulated by the law projects about this situation. This context also reflects the few literature produced on Physical Education Early Childhood

\footnotetext{
${ }^{1}$ Profa. Adjunta do Instituto de Educação da Universidade Federal do Rio Grande (FURG), Líder do Grupo Educação, Corpo, Cultura do Movimento e Sociedade (ECCOS), camilaborges@ hotmail.com

${ }^{2}$ Profa. de Educação Física da educação infantil e anos iniciais da Secretaria Municipal de Educação de Rio Grande - SMED, Membro do Grupo Educação, Corpo, Cultura do Movimento e Sociedade (ECCOS) jo_pedagoga@yahoo.com.br

${ }_{3}^{3}$ Profa. Adjunta do Instituto de Educação e do Programa de Pós-Graduação em Educação da Universidade Federal do Rio Grande (FURG), Líder do Grupo Educação, Corpo, Cultura do Movimento e Sociedade (ECCOS), angelabersch@gmail.com.br
} 
Education in Rio Grande. We conclude that by directing our look at history knowing and recognizing it, we can identify its strengths and weaknesses to think strategies in order to qualify the teaching profession. This writing allows us to form a knowledge that incites future reflections and actions in this field.

Keywords: Physical Education; Childhood Education; Childhood.

\author{
COSTITUCIÓN DE LA EDUCACIÓN FÍSICA EM LA EDUCACIÓN INFANTIL EM EL \\ MUNICIPIO DE RIO GRANDE (RS): PERSPECTIVAS PARA UMA SOCIOLOGÍA DE LA \\ INFANCIA
}

\begin{abstract}
RESUMEN
Este artículo tiene como objetivo discutir la constitución del lugar de Educación Física en Educación Infantil en el municipio de Rio Grande, estado de Rio Grande do Sul. Para ello se utilizaron trabajos académicos, licitaciones en concursos públicos municipales y documentos legales. Encontramos que la inserción del docente de Educación Física en esta etapa de la docencia en el municipio es reciente, ya que el primer nombramiento en cargo efectivo se realizó en 2015, contando actualmente con 16 docentes efectivos. Este hecho no sirve a todas las escuelas municipales, pero es parte de un movimiento impulsado por los proyectos de ley que abordaron este tema. Este escenario también refleja la escasa literatura producida sobre Educación Física en la Educación Infantil local. Concluimos que al dirigir nuestra mirada a la historia (re) conocerla, podemos identificar sus fortalezas y debilidades para pensar estrategias con el fin de calificar la acción docente. Además de registrarlo, nos permite conformar un marco teórico que incita a futuras reflexiones y acciones en este campo.
\end{abstract}

Palabras clave: Educación Fisica; Educación Infantil; Infancia.

\title{
INTRODUÇÃO
}

A promulgação da Lei de Diretrizes e Bases da Educação Nacional (LDB) nº 9.394/96 trouxe avanços significativos no que se refere à organização educacional no País, dentre elas, incorporou a Educação Infantil à educação básica.

Essa reconfiguração nos fez inferir que a Educação Física, na condição de componente curricular obrigatório da educação básica, seria automaticamente um novo espaço de atuação docente. Entretanto, Martins (2018) alerta para o fato de haver um equívoco no que diz respeito a essa dedução, uma vez que, somente em 2001, com a Lei 10.328, o termo "obrigatório" foi incluído na redação. O autor associa a esse fato o reflexo do desempenho brasileiro das Olimpíadas de 2000 na Austrália, que não obteve medalha de ouro.

O mesmo autor ainda destaca outra questão que reverbera nesse cenário: a Lei 11.738/2008, a "Lei do Piso", que assegura o piso salarial ao profissional do magistério público da educação básica em território nacional, garantindo a remuneração mínima conforme titulação, estabelecendo que, na “jornada de trabalho, observar-se-á o limite máximo de 2/3 (dois terços) da carga horária para o desempenho das atividades de interação com os 
educandos". Dessa forma, a destinação de 1/3 (um terço) das atividades extraclasses provoca uma lacuna na carga horária de aulas que precisa ser preenchida com a presença de outros profissionais, resultando na inserção das aulas de Educação Física e Artes, com professores especialistas nas disciplinas.

Outro aspecto relevante se deve à LDB não apresentar quem seria o responsável por ministrar as aulas de Educação Física, tanto para a Educação Infantil quanto para os anos iniciais do ensino fundamental. Fato esse que muda com o Projeto de Lei do Senado 443/2012, de autoria do Senador Lindbergh Farias, filiado ao Partido dos Trabalhadores do Rio de Janeiro, cuja redação afirma que "os conteúdos curriculares da disciplina Educação Física no ensino infantil, fundamental e médio serão ministrados exclusivamente por Professores de Educação Física, licenciados em nível superior” (BRASIL, 2012). Os estados e municípios teriam, a partir daquela data, 10 (dez) anos para sua adequação. Esse projeto é complementado por outro de autoria do Deputado Federal Otavio Leite (PSDB/RJ) que, nesse mesmo viés, com a PLC 116/2013, reduz esse tempo de adequação para 5 (cinco) anos (BRASIL, 2013).

Diante do cenário apresentado, este artigo tem por objetivo discorrer sobre a constituição do lugar da Educação Física na Educação Infantil, no município do Rio Grande, estado do Rio Grande do Sul. Para tanto, realizamos a análise dos documentos norteadores em níveis nacionais - sobre a constituição da Educação Infantil municipal até a inserção da Educação Física em seu currículo - e municipais - que contemplaram leis, projetos de leis e os dois editais dos concursos públicos municipais referentes ao cargo de professor de Educação Física para atuar na Educação Infantil.

A perspectiva da sociologia da infância, que dá contorno a esse trabalho, está apoiada em alguns estudiosos que entendem a autoria das crianças nas construções sócio-histórico e culturais (SARMENTO, 2004; CORSARO, 2011; PROUT, 2010) e, sobretudo, dão destaque à dimensão corporal (JAMES, JENKS e PROUT, 2000), por muito tempo e por muitos dicotomizada. Notabilizar a criança é entendê-la de forma plural, diversa e múltipla, tal qual acontece com as infâncias; do contrário, corremos sério risco de nos equivocarmos com as concepções emergentes (SARMENTO, 2013).

Para tanto, entendemos serem necessários dois caminhos para compreendermos esse processo histórico: o primeiro contextualizando como se configurou a Educação Infantil no município do Rio Grande; o segundo, elencando alguns elementos presentes nos concursos para professores/as de Educação Física municipal e documentos norteadores elaborados para a atuação docente. 


\section{CONTEXTUALIZAÇÃO DA EDUCAÇÃO INFANTIL NO MUNICÍPIO DO RIO GRANDE}

Para tratar da constituição da Educação Física na Educação Infantil no município de Rio Grande, sentimos necessidade de tecer um breve histórico de como essa etapa de ensino foi se constituindo até a inserção da Educação Física em seu currículo. É possível ponderar que os acontecimentos e concepções em torno da infância, no microcontexto desse município, foram semelhantes àqueles que aconteciam em um espectro nacional e mundial. Para situarmos a educação, de forma especial a Educação Infantil, é importante contextualizarmos, brevemente, as dimensões sócio-histórico e econômicas deste município. Para isso, utilizamos como base algumas pesquisas produzidas no cenário acadêmico (BORGES, 2015; VALLE, 2017), que perpassaram o campo da educação até o surgimento da Educação Infantil municipal.

No início do século XIX, a dimensão educacional rio-grandina era vista pela camada privilegiada dessa sociedade, como uma arma para capacitar e qualificar a força de trabalho imprescindível para o progresso. Já a classe operária percebia a educação como um meio (se não o único) para a sua independência, seja de forma individual, pela ascensão social, seja coletivamente, pela organização de lutas (VALLE, 2017).

Nessa lógica, Valle (2017) afirma que era necessário "preparar" o proletariado para o labor, formação essa que deveria iniciar na infância, por meio da educação para o trabalho, a fim de que as crianças pudessem acessar a sociedade como trabalhadores disciplinados e obedientes às leis.

Para Borges (2015 p. 86), "até meados do século XIX, o atendimento à infância na cidade de Rio Grande caracterizou-se por uma fase caritativa", permeado por práticas de assistência. Para a autora, as primeiras instituições com características de atendimento infantil surgiram, no município no século XIX, com a Roda dos Expostos (1843) e o Asilo de Órfãs Coração de Maria (1861). Este segundo foi criado com o intuito de acolher as meninas não adotadas colocadas na Roda dos Expostos, tendo como objetivo a salvação das almas dessas crianças.

Áries (1981) afirma que, a partir do século XVIII, por meio das orientações da igreja católica, novos modelos de relações com crianças foram sendo instituídos, como o de família. Nesse período, a infância passou a ocupar outro espaço e o tempo dos adultos. A sociedade passou a criar espaços específicos para as crianças, dentre eles, a escola, visando à educação e à disciplina moral desses pequenos sujeitos, que passaram a fazer parte de uma categoria social, 
a infância (SARMENTO, 2004).

No século XX, Rio Grande foi considerado como um importante centro urbano. O seu crescimento econômico foi impulsionado pelo porto e pelo parque fabril, caracterizado pelo estabelecimento das indústrias pesqueira, têxtil, metalúrgica, tabagista, calçadista, entre outras (MARTINS, 2006).

Pessoas de diferentes culturas fizeram morada no município. Entretanto, muitas doenças, também, se desenvolveram devido à falta de infraestrutura para atender a toda a demanda. Com isso, muitas crianças ficaram órfãs, principalmente, durante as epidemias de Febre Amarela e Varíola em meados de 1900 (TORRES, 2015). Diante da calamidade, foi criado o "Asylo das Orphans São Benedito" (1900), que abrigava meninas de 0 a 15 anos e provia estudos, ensinando-as a ler e a escrever (BORGES, 2015).

Nessa época, ainda havia um estatuto de caridade e filantropia envolvido ao acolher essas crianças, mas, ao mesmo tempo, novos discursos circulavam pela sociedade, produzindo outras formas de pensar a educação para elas, entendendo-as enquanto uma categoria, as quais apresentam suas características e necessidades particulares. O "Dispensário Infantil Augusto Duprat" (1932) apresentava essas características e finalidades: zelar pela vida, cuidando da saúde, investindo em normas e regras de conduta e educando para a vida em sociedade (BORGES, 2015).

A criança começou, então, a ser alvo de investimento e intervenção para o futuro. "Através de ações tanto do Estado quanto da sociedade civil, a infância é transformada num projeto" (PROUT, 2010, p. 22). Várias áreas do conhecimento se dedicaram a estudar sobre as crianças que passaram a ser analisadas, observadas e pesquisadas, refletindo na produção de uma gama de informações, por meio de livros, palestras e artigos de "como as crianças se desenvolvem e podem ser moldadas em futuros cidadãos e trabalhadores" (PROUT, 2010, p. 22).

Nessa lógica, surgiram vários espaços nos quais se concentraram grupos de crianças para que pudessem ser orientadas, educadas e, sobretudo, supervisionadas pelos adultos. Entretanto, os estudos realizados eram sobre as crianças e não com elas ou a partir do olhar delas. Fato que reverberou em que o "século da criança deu muito mais atenção à contribuição da sociedade para as crianças do que à contribuição destas para a sociedade" (PROUT, 2010, p. 34).

Nos anos 30, um novo sistema educacional começou a ser implantado nas cidades, sobretudo, com a implementação de um novo Governo, o qual criou um Ministério do Trabalho, Indústria e Comércio e fez emergir as creches, com novas configurações para o atendimento às crianças. Entretanto, esses espaços foram criados com o intuito de cuidado e zelo às crianças 
que eram filhas das funcionárias das indústrias e fábricas. As instituições mantenedoras dessas escolas eram as próprias fábricas e indústrias dos municípios (BORGES, 2015).

Em Rio Grande, a Fábrica Têxtil Rheingantz e Valter foi um exemplo disso. Com a necessidade de contratação de mulheres para o trabalho fabril, a Creche Rheingantz foi erguida em meados dos anos 40, nas proximidades da fábrica, com o objetivo de cuidado das crianças. Não há indícios de uma proposta pedagógica direcionada àqueles sujeitos. Tal espaço foi fechado em 1962, após falência de diversas fábricas instaladas na cidade (BORGES, 2015).

Ao mesmo tempo em que uma crise se instaurava no município, com fábricas e indústrias fechando, a atividade pesqueira movimentava o setor econômico. Com ela, iniciouse a construção de diferentes creches, e a primeira delas, o Centro Educacional Fraternidade (1962), com foco de promover aulas para meninas e mães daquela região. Somente em meados de 1979, esse espaço passou a atender, também, as crianças. Esse espaço tinha como foco ensinar normas de condutas, posturas e limites, formando crianças e adolescentes para serem sujeitos morais. Considerava-se que deveria ser combatida a pobreza e a marginalização desde muito cedo, nesse sentido, o Centro passou a atender, também, aos bebês e às crianças bem pequenas em diferentes partes da cidade (BORGES, 2015).

De acordo com a Proposta Pedagógica Municipal para a Educação Infantil (RIO GRANDE, 2015, p. 8)

Muitas das instituições de Educação Infantil no município iniciaram suas atividades ligadas à Assistência Social e à Saúde. [...] Porém, após a vinculação de creches e pré-escolas, à Secretaria de Educação, passou-se a lançar um olhar mais específico a este atendimento, principalmente no que tange ao profissional que desempenha o cuidado e educação das crianças.

A partir dos anos de 1980, novas formas de pensar a Educação Infantil começaram a ser delineadas, principalmente, com a implantação de um novo Governo, o qual promulgou a Constituição Federal em 1988 (BRASIL, 1988), que passou a determinar que o Estado proveria a educação de todas as crianças com a implantação de creches e pré-escolas. A partir desse momento, vários foram os documentos oficiais criados com o intuito de legislar e orientar as ações pedagógicas nessa etapa de ensino.

Com isso, há uma consolidação da Educação Infantil, em nível nacional, se solidificando com a implementação do Estatuto da Criança e Adolescente (1990) e a LDB, que colocou essa etapa de ensino como a primeira da educação básica (BRASIL, 1996).

Borges (2015) coloca que os documentos legais reverberaram na educação das crianças 
pequenas em Rio Grande, ao longo da década de 90, com a inserção de turmas de Educação Infantil em diferentes Instituições de ensino municipais. Uma nova população passou a ser atendida nesses espaços, agora, com uma proposta pedagógica envolvida e com professores habilitados.

Assim, a Educação Infantil ganhou, cada vez mais, espaço no país e no município do Rio Grande. Um dos fatos que nos faz perceber esse investimento, atualmente, está previsto na primeira meta do Plano Nacional de Educação (2014-2024) e do Plano Municipal de Educação (2015-2025), os quais trazem, enquanto estratégias, o investimento em multiprofissionais para atuarem com essa etapa de ensino.

\section{EDUCAÇÃO FÍSICA NA EDUCAÇÃO INFANTIL NO MUNICÍPIO DO RIO GRANDE: A INSERÇÃO DE NOVOS PROFESSORES/AS}

Como dito anteriormente, a Educação Infantil vem ganhando, cada vez mais, espaço no território nacional, bem como no município do Rio Grande. Isso se deve ao fato de diferentes documentos oficiais começarem a ser implementados para atender às crianças de 0 (zero) até 6 (seis) e, posteriormente, até 5 (cinco) anos de idade.

Essa alteração dada à redação da primeira versão da LDB se refere à Educação Infantil como primeira etapa da educação básica, que tinha como "finalidade o desenvolvimento integral da criança de até 6 (seis) anos, em seus aspectos físico, psicológico, intelectual e social, complementando a ação da família e da comunidade" (BRASIL, 1996). No entanto, essa redação foi alterada com a Lei $\mathrm{n}^{\circ} 12.796$, cuja idade passou a ser até 5 (cinco) anos (BRASIL, 2013).

Os documentos, os quais explicitam interesse com a formação das crianças, foram balizadores da ação pedagógica nessa etapa de ensino: o Referencial Curricular Nacional para a Educação Infantil (RCNEI) (BRASIL, 1998); as Diretrizes Curriculares Nacionais para a Educação Infantil (DCNEI) (BRASIL, 2010) e a Base Nacional Comum Curricular (BNCC) (BRASIL, 2017).

O município do Rio Grande dispõe de dois documentos com dados da realidade local para pensar propostas pedagógicas específicas: Proposta Pedagógica Municipal para a Educação Infantil (PPMEI) (RIO GRANDE, 2015) e o Documento Orientador Curricular do Território Rio-grandino (DOCTR) (RIO GRANDE, 2019).

Nesse processo, o Plano Nacional de Educação (Lei n ${ }^{\circ}$ 13.005/ 2014) e o Plano 
Municipal de Educação (Lei nº 7.911/2015) trazem algumas metas a serem implementadas até o ano de 2024. Especificamente, na primeira meta do Plano Municipal de Educação, tem-se como proposta: "universalizar, até 2016, a Educação Infantil na pré-escola para as crianças de 04 a 05 anos de idade e ampliar a oferta de Educação Infantil em creches, de forma a atender, no mínimo, $50 \%$ das crianças de até 03 anos, até o final da vigência deste PME" (RIO GRANDE, 2015, p. 45). Para tanto, definiu-se como estratégias o investimento em multiprofissionais, bem como em sua formação continuada. No Plano Municipal de Educação, destacamos as seguintes estratégias:

1.6 - realização de concurso público com nomeação que contemple os diversos setores da escola, como: bibliotecários(as), secretários(as), auxiliares com formação mínima de magistério, a fim de minimizar possíveis desvios de função; $[\ldots]$

1.8) promover a formação inicial e continuada dos (as) profissionais da educação infantil, garantindo, progressivamente, $\mathrm{o}$ atendimento por profissionais com formação superior;

1.9 - garantir o atendimento às crianças da Educação Infantil por equipe multiprofissional, em número suficiente para atender toda a demanda escolar; 1.10 - ampliação do quadro de recursos humanos, a fim de garantir a efetivação da hora-atividade para os professores da Educação Infantil, através de concurso público, até o $2^{\circ}$ ano de vigência deste Plano (BRASIL, 2014).

Embora ambos os Planos não especifiquem o/a professor/a de Educação Física enquanto parte da equipe multiprofissional que estaria atuando com as turmas de Educação Infantil, dois concursos foram realizados contemplando o cargo de professor de nível II - Educação Física Educação Infantil e Anos Iniciais no município do Rio Grande, nos anos de 2014 e 2019.

O primeiro concurso foi lançado no dia 06/09/2014, no Edital $n^{\circ} 02 / 2014$, com seu resultado final homologado na data de 25/02/2015, tendo a primeira nomeação realizada em 3/3/2015. O segundo concurso foi publicado no Edital $n^{\circ} 2 / 2019$, em 27/11/2019, tendo resultado final homologado em 20/02/2020. Em ambos os editais, estavam previstas cotas para pessoas com deficiência e afro-brasileiros (pretos e pardos).

No Edital $n^{\circ}$ 02/2014 para o cargo supracitado, a exigência era de formação em Licenciatura Plena em Educação Física, havendo disposição de duas vagas somadas ao cadastro reserva, para trabalhar 20 horas/aula semanais. Esse mesmo edital previa 40 questões objetivas, valendo 2,25 pontos cada questão. $\mathrm{O}$ critério de aprovação estava atrelado à nota igual ou maior que 45 pontos, acrescidas da nota da prova de títulos.

Com os programas de estudos das provas, foi possível verificar que o Edital n 2/2014 traz, em seu programa, questões de língua portuguesa e legislação geral, abarcando LDB, 
DCNEI, ECA e a Lei Orgânica do Município do Rio Grande e conhecimentos pedagógicos, que contemplaram assuntos específicos das temáticas:

1. História e concepções da Pedagogia, da Educação e da Educação Integral. 2. O contexto das relações entre a escola e comunidade educativa. 3. O saber ser, o saber conhecer e o saber fazer do professor. 4. Ensino, currículo e aprendizagem: diretrizes, concepções e práticas pedagógicas. 5. O processo de inclusão escolar 6. Indisciplina e fracasso escolar 7. Planejamento, Projeto Político- Pedagógico. Projetos de Trabalho, Planos de Ensino. 8. Avaliação da aprendizagem. 9. Interdisciplinaridade (RIO GRANDE, 2014, p. 25).

O Edital nº 2/2019 se referiu ao mesmo cargo - professor de nível II - Educação Física - Educação Infantil e Anos Iniciais - com as mesmas exigências para tomar posse, Licenciatura Plena em Educação Física, com 20 horas/aula de carga horária semanal. O referido edital previa uma vaga somada ao cadastro reserva.

Quanto aos títulos, a pontuação poderia atingir, no máximo, 10 pontos, com a seguinte distribuição: doutorado, 3,5 pontos; mestrado 3,0; especialização 1,5 e cursos de extensão, com carga horária mínima de 40 horas, concluída até quatro anos antes do edital, contabilizava 1 ponto, podendo ser até dois (RIO GRANDE, 2019).

Conforme ainda consta no edital, a prova objetiva foi estruturada de forma diferente ao acrescentar cinco questões de conhecimentos de informática e cinco questões de raciocínio lógico, as quais foram retiradas em uma retificação do edital, além das 10 de legislação, 10 de língua portuguesa e 10 de conhecimentos específicos. Apesar da redução do número de questões de conhecimentos específicos, o peso era 3,4, enquanto as demais, 2,2.

Uma mudança em relação ao programa previsto para as questões de conhecimento pedagógico se deve aos temas abordarem conteúdos específicos da área da Educação Física, conforme indicado no Edital n ${ }^{\circ}$ 2/2019:

O lúdico nas atividades de aprendizagem. $O$ papel do professor e do aluno no processo de ensino e aprendizagem. História e concepções da Pedagogia, da Educação e da Educação Integral. O contexto das relações entre a escola e comunidade educativa. $\mathrm{O}$ saber ser, o saber conhecer e o saber fazer do professor. Ensino, currículo e aprendizagem: diretrizes, concepções e práticas pedagógicas. O processo de inclusão escolar Indisciplina e fracasso escolar. Projetos de Trabalho, Planos de Ensino. Avaliação da aprendizagem. Interdisciplinaridade. Inovação na sala de aula. O currículo escolar; a prática educativa e a função pedagógica. Planejamento, projeto de ensino aprendizagem e projeto político pedagógico. Conhecimentos específicos e diferentes possibilidades de inserção na escola das Culturas Corporais de Movimento: jogos, esporte, ginástica, lutas, dança e capoeira. Abordagens pedagógicas, concepção de aprendizagem, objetivos, 
planejamento, metodologia, conteúdos e avaliação. O desenvolvimento motor na infância e adolescência. Atividade física e saúde. Inclusão dos alunos com deficiência na Educação Física: principais características, implicações e considerações sobre a prática de atividades físicas. Educação Física e socorros de urgência. Resposta fisiológicas ao exercício físico (RIO GRANDE, 2019, p. 21). Grifo nosso

Destacamos que os temas incluídos - grifados acima -, específicos da área de Educação Física, não tinham indicação bibliográfica, diferentemente dos temas já abordados.

O primeiro concurso teve cinquenta e três professores/as aprovados e quinze nomeados para atuarem em turmas de Educação Infantil e nos Anos Iniciais. Já o segundo teve quarenta e cinco professores aprovados e um nomeado até a escrita deste artigo.

Embora tenha um quadro efetivo de professores/as de Educação Física atuando em turmas de Educação Infantil na rede municipal, é possível ponderar que essa demanda ainda não cobre todas as escolas que atendem a esse público, pois, até o momento, o município conta com quatorze professores atuantes entre turmas de Educação Infantil e anos iniciais, oriundos desses dois concursos específicos, desconsiderando aqueles professores que apresentam complementação nas suas cargas horárias.

A inserção dos/as professores/as de Educação Física habilitados a atender turmas de Educação Infantil é um processo novo no município e o trabalho pedagógico desses/as professores/as pode ser considerado como construção de cada um deles, juntamente com as escolas em que estão inseridos/as, além da busca por uma identidade coletiva. Esse elemento pode ser pensado a partir da pesquisa produzida por Santos (2016), o qual deu voz a três professores/as de Educação Física nomeados para atuarem em turmas de Educação Infantil e anos iniciais, oriundos do Edital $n^{\circ}$ 2/2014. O autor identificou que a Educação Física, nessas etapas, começou a se estruturar com a chegada dos docentes.

Segundo as narrativas desses/as professores/as, os espaços, em termos de estrutura física, foram sendo construídos pelos próprios/as docentes a partir dos seus entendimentos de Educação Física, as quais perpassam pelas práticas corporais. Cada uma das escolas apresenta um espaço diferente para o/a professor/a intervir. $\mathrm{O}$ autor identificou, também, que, por se tratar de um espaço no qual recém se adentrou, os/as professores/as apontaram para a necessidade de uma estrutura física e material, bem como da elaboração de documentos com orientações dos caminhos a serem percorridos ou um currículo mínimo a ser seguido.

Sayão (2002), Cavalaro e Muller (2009), Martins (2018), Martins et alli (2018), Mello et alli (2015), Mello et alli (2016) e Mello et alli (2018) ressaltam que, para a Educação Física se efetivar na educação infantil, é preciso pensá-la de maneira articulada com os diferentes 
campos do saber, não a delimitando como um momento específico com tempo predeterminado, cuja aula seja ministrada por um professor "especialista". É preciso avançar na perspectiva de que tanto as crianças quanto os professores são sujeitos produtores de cultura que devem, portanto, articular os diferentes "saberes e práticas" oriundos dos diversos campos do conhecimento (SAYÃO, 2002, p. 65).

Santos (2016) identificou, também, a partir das narrativas, que os/as professores/as se utilizam-se de elementos da abordagem desenvolvimentista como viés de orientação para a prática pedagógica. Essa abordagem está associada a uma Educação Física que prioriza o ensino de habilidades motoras básicas. Além disso, no trabalho, são trazidos relatos do quanto a Educação Física pode auxiliar nas tarefas de coordenação motora fina realizadas com os/as professores/as unidocentes. Santos (2016) ainda identificou uma preocupação com organização curricular e planejamento com semelhanças, mas, ao mesmo tempo, não conseguiu perceber a presença da cultura como elemento dessa elaboração.

Nessa perspectiva, Sayão (2002) ressalta que o local em que se vive deva ser explorado ao longo das propostas a serem propiciadas às crianças, além do estímulo à permissividade de vivenciar os jogos e brincadeiras, vislumbrando a construção de uma cultura infantil.

Tal convicção também foi apontada por Ritcher e Vaz (2010), que entendem que essas experimentações propostas pela Educação Física, nas infâncias, “deveria ocupar-se de lugares e temas para além daqueles que historicamente demarcaram (e demarcam, ainda) seu locus de atuação: a rua, a quadra, o campo, ou, noutros termos, o ensino dos esportes, a recreação ou as práticas psicomotoras que, no contexto da educação infantil" (p. 66) superando ainda a delimitação de um tempo definido para essas vivências.

Nesse sentido, o Documento Orientador Curricular do Território Rio-grandino (RIO GRANDE, 2019) que foi organizado, a partir da BNCC, traz os direitos da aprendizagem e os campos da experiência. Para Martins (2018) e Mello et alli (2016), a BNCC não organiza essa etapa de ensino de forma disciplinar, o que confere outra maneira de se pensar a Educação Física nesse espaço, bem como a concepção de criança. Sobre isso, concordamos com Martins et alli (2018) que, ao analisarem os campos epistemológicos que balizam as pesquisas da Educação Física na Educação Infantil, identificaram que "as vozes das crianças têm sido silenciadas nas pesquisas sobre a infância" (p.150). Fato que é preocupante, pois pode evidenciar importantes equívocos em termos de achados científicos e, sobretudo, ressalta que muitas pesquisas são realizadas 'sobre' ou 'para' as crianças, não 'com' elas.

A BNCC coloca uma perspectiva pautada na sociologia da infância, vigente, também, 
nas DCNEI. Ter essa concepção significa olhar "para" as crianças e suas inter e intra relações; considerar que elas são produtoras de culturas e assim como são influenciadas pelas culturas também exercem influência sobre elas (SARMENTO, 2008); são atores ativos e agem sobre bens culturais, os quais elas ressignificam, processo que Corsaro (2011) denomina de reprodução interpretativa.

Essa mútua e bidirecional influência da criança sobre a cultura anunciada pelos estudiosos da sociologia da infância tem influenciado os estudos no âmbito da Educação, inclusive da Educação Física. Nesse sentido, para haver um efetivo recrudescimento da compreensão da potencialidade da Educação Física, na Educação Infantil, é necessário que haja uma mudança na forma como ela está sendo concebida, não a pensando como uma disciplina isolada em seu currículo, mas enquanto mais uma área que, em conjunto com as demais, que Mello et alli (2018) denominam como um trabalho articulado entre docentes e seus saberes específicos. Entendemos com os autores e concordamos com eles que essa perspectiva consiga dar conta de pensar em propostas pedagógicas que levem em consideração as infâncias que fazem parte do dia a dia, as suas culturas e formas de perceber o mundo que as cerca.

\section{CONSIDERAÇÕES FINAIS}

O intuito deste texto foi discorrer sobre a constituição do lugar da Educação Física na Educação Infantil, no município do Rio Grande, estado do Rio Grande do Sul. Realizamos um exercício de narrar uma história de como foi sendo construída a educação das crianças nesse município, perpassando pela emergência da Educação Infantil até a inserção da Educação Física em seu currículo. Desse modo, trouxemos, além de estudos acadêmicos, aspectos que julgamos relevantes dos documentos legais que orientam e dão diretrizes para a estrutura e organização pedagógica da Educação Física no âmbito da educação infantil.

Compreender o caminho percorrido e os meandros da metodologia adotada na realização de concursos que selecionam o/a professor/a de Educação Física possibilita maior entendimento de concepções, currículos, conceitos e pedagogias desejadas no direcionamento dos processos pedagógicos junto às crianças na Educação Infantil. Nesse sentido, observamos que, embora os editais dos concursos anunciassem uma gama de conhecimentos, havia uma preocupação com os diferentes aspectos da criança: afetivo, social, motor, biológico, cultural etc.

Por outro lado, evidenciou-se que, no fazer docente, alguns professores/as nomeados no primeiro concurso público, no município de Rio Grande, utilizam, no seu processo ensino- 
aprendizagem, elementos da abordagem desenvolvimentista que preconiza as habilidades motoras (SANTOS, 2016). Fato que pode estar atrelado às lacunas da formação docente para esse campo de atuação que, de certa maneira, é recente e cujos avanços caminham de maneira tímida. Por outro lado, a escolha por essa abordagem também pode ser uma opção de concepção, mas que, conforme os relatos, acompanha uma ideia da Educação Física como complementar ao trabalho do/a unidocente, ou, ainda, reflexos de uma perspectiva esportivista da qual muitos/as professores/as ainda são reféns.

O "ser" docente, na Educação Infantil, implica e envolve uma gama de conhecimentos, vivências, experiências que vão constituindo e (re)construindo a práxis pedagógica do professor de Educação Física nessa etapa. Embora a história da Educação Física, nessa etapa de ensino, no município do Rio Grande, ainda seja embrionária, conhecê-la e contá-la nos permite identificar toda a sua potência em termos de práticas pedagógicas e nos faz pensar ações a serem construídas em nível da formação inicial e continuada dos/as professores/as que estão adentrando nas doçuras e agruras da Educação Infantil.

\section{REFERÊNCIAS}

ARIÈS, Philippe. A História Social da criança e da família. 2a . Ed. Rio de Janeiro, RJ: Guanabara, 198.

BRASIL. Secretaria de Educação Fundamental. Parâmetros curriculares nacionais: Educação física / Secretaria de Educação Fundamental. - Brasília: MEC/SEF, 1997.

. Diretrizes Curriculares Nacionais para a Educação Infantil. Ministério da Educação. -

Brasília: MEC, SEB, 2010.

. Lei de Diretrizes e Bases da Educação n ${ }^{\circ} 9.394$ de 20 de dezembro de 1996.

. Lei de Diretrizes e Bases da Educação no 10.328, de 12 de dezembro de 2001.

. Lei de Diretrizes e Bases da Educação no 12.796, de 4 de abril de 2013.

. Congresso Nacional. Projeto de Lei do Senado no 443 de 2012. Altera a Lei n. ${ }^{\circ}$ 9.394, de 20

de dezembro de 1996, que estabelece as diretrizes e bases da educação nacional - LDB, para dispor

sobre educação física no ensino infantil, fundamental e médio. Disponível em:

https://legis.senado.leg.br/sdleg-

getter/documento?dm=4402434\&ts=15940137174339\&disposition=inline. Acesso em: 12 abr. 2021.

Texto original.

. Projeto de Lei da Câmara no. 116 de 2013, no 6.520/2009. Altera a Lei no 9.394, de 20 de dezembro de 1996, que estabelece as diretrizes e bases da educação nacional - LDB, para dispor sobre a formação dos professores de educação física na educaçãp básica. Disponível em:

https://legis.senado.leg.br/sdleggetter/documento?dm=4291434\&ts=1593995636134\&disposition=inline. Acesso em: 12 abr. 2021. Texto original.

. Lei Federal 13.005, de 25 de junho de 2014. Aprova o Plano Nacional de Educação - PNE e dá outras providências. Brasília, DF, 25.

BORGES, Juliana Diniz Gutierrez. As práticas de atendimento à infância no município do Rio 
Grande: um recuo ao passado para problematizar o presente. 2015. Dissertação (Mestrado em Educação) - Universidade Federal do Rio Grande, 135p.

CORSARO, William. A. Sociologia da infância. 2. ed. Porto Alegre: Artmed, 2011.

CAVALARO, Adriana Gentilin. MULLER, Verônica Regina. Educação física na educação infantil: uma realidade almejada. Educar, Curitiba, n. 34, p. 241-250, 2009. Editora UFPR

JAMES, Allison; JENKS, Chris; PROUT, Alan. O corpo e a infância. In: KOHAN, Walter. O.; KENNEDY, David. Filosofia e infância: possibilidades de um encontro. 2. ed. Petrópolis, RJ: Vozes, 2000. p.207-238

MARTINS, Rodrigo Lema Del Rio. O lugar da educação física na educação infantil. 2018. Tese (Doutorado em Educação Física) - Universidade Federal do Espírito Santo, Centro de Educação Física e Desportos. 211p.

MARTINS, Rodrigo Lema Del Rio; BARBOSA, Raquel Firmino Magalhães; MELLO, André da Silva. Educação física e educação infantil: o estado do conhecimento sobre a formação docente.

Arquivos Brasileiros de Educação Física, Tocantinópolis/TO, v. 1, n. 1, p. 135-155, jan./jul. 2018.

MARTINS, Solismar Fraga. Cidade do Rio Grande: industrialização e urbanidade (1873-1990). Rio Grande: FURG, 2006.

MELLO, André da Silva; ZANDOMÍNEGUE, Bethânia Alves Costa; VIEIRA, Aline de Oliveira; SILVA, Angélica Caetano da; ASSIS, Livia Carvalho de; BARBOSA, Raquel Firmino Magalhães; MARTINS, Rodrigo Lema Del Rio. Pesquisas com crianças na educação infantil: diálogos interdisciplinares para produção de conhecimentos. Motrivivência, Florianópolis, v. 27, n. 45, p. 28 43, set. 2015.

MELLO, André da Silva; ZANDOMÍNEGUE, Bethânia Alves Costa; BARBOSA, Raquel Firmino Magalhães; MARTINS, Rodrigo Lema Del Rio; SANTOS, Wagner. Educação infantil e a base nacional comum curricular: interfaces com a educação física. Motrivivência, Florianópolis, v. 28, n. 48, p. 130-149, set. 2016.

MELLO, André da Silva; MARTINS, Rodrigo Lema Del Rio; JORGE, Renata Silva; ZANDOMÍNEGUE, Bethânia Alves Costa. Educação física na educação infantil: do isolamento pedagógico à articulação com outras áreas do conhecimento. Revista Kinesis, Santa Maria v. 36, n.3, p. 15-27, set-dez. 2018.

VALLE, Hardalla Santos do. O ensino de ofícios na cidade do Rio Grande (1889- 1930): uma análise sobre a infância desvalida. Tese (Doutorado) — Programa de Pós-Graduação em Educação, Faculdade de Educação, Universidade Federal de Pelotas, 2017.

PROUT, Alan. Participação, políticas e as condições da infância em mudança. In: MÜLLER, Fernanda (org). Infância em perspectiva: políticas, pesquisas e instituições. São Paulo: Cortez, 2010. RIO GRANDE. Plano municipal de educação 2015-2025. Disponível em: https://www.riogrande.rs.gov.br/smed/wp-content/uploads/2015/06/20150621-pme_atualizado.pdf Acesso em: 12 abr. 2021.

. Edital de concurso público no. 02/2014. Rio Grande: Secretaria de Município da Educação. Disponível em: www.riogrande.rs.gov.br/concursos/arquivos/edital/edital_de_abertura_sme.pdf. Acesso em: 31 jan. 2021.

. Edital de concurso público no. 02/2019. Rio Grande: Secretaria de Município da Educação. Disponível em: https://ibrasp.selecao.net.br/uploads/256/concursos/32/anexos/0d535e00a62430983ddb5437dd53950dc. pdf Acesso em: 31 jan. 2021.

. Prefeitura municipal do Rio Grande. Secretaria de município da educação. Documento orientador curricular do território riograndino: educação infantil [Recurso Eletrônico] / Felipe Alonso dos Santos (org) [et al]. Il. capa por Michelle Coelho Salort - Rio Grande: SMED, 2019. 229 p. RITCHER, Ana Cristina; VAZ, Alexandre Fernandez. Educação física, educação do corpo e pequena infância: interfaces e contradições na rotina de uma creche. Movimento, Porto Alegre, v. 16, n. 01, p. 
53-70, janeiro/março de 2010.

SANTOS, Tayson Pedroso dos. Narrativas de professores(as) de educação física atuantes em turmas de educação infantil e anos iniciais em escolas da cidade do Rio Grande. Trabalho de Conclusão de Curso (Instituto de Educação) - Universidade Federal do Rio Grande. 2016.

SAYÃO, Deborah Thomé. Corpo e movimento: notas para problematizar algumas questões relacionadas à educação infantil e à educação física. Rev. Bras. Cienc. Esporte, Campinas, v. 23, n. 2, p. 55-67, jan. 2002.

SARMENTO, Manuel J. Sociologia da infância: correntes e confluências. In: SARMENTO, Manuel. J.; GOUVÊA, Maria Cristina. S. Estudos da Infância: educação e práticas sociais. Petrópolis: Vozes, 2008.

TORRES, Luiz Henrique. História do município do Rio Grande. Rio Grande: Pluscom, 2015. 